\title{
Matrix metalloproteinase- 9 overexpression is closely related to poor prognosis in patients with colon cancer
}

\author{
Bo Yang ${ }^{1 \dagger}$, Fuqiu Tang ${ }^{2 \dagger}$, Bicheng Zhang ${ }^{1}$, Yong Zhao ${ }^{1}$, Junming Feng ${ }^{3 *}$ and Zhiguo Rao ${ }^{1 *}$
}

\begin{abstract}
Background: Matrix metalloproteinase-9 (MMP-9) is an important member of the matrix metalloproteinase family and is considered to be involved in the invasion and metastasis of cancer cells. This study analyzed the expression of MMP-9 in colon cancer patients and the relationship between this expression and clinicopathological features and survival.

Methods: We immunohistochemically investigated 68 specimens of colon cancer tissues and corresponding distal normal mucosa tissues using MMP-9 antibody. Then, the correlation between MMP-9 expression and clinicopathological features and its prognostic relevance were determined.

Results: The expression rate of MMP-9 in colon cancer tissues was significantly higher than that in distal normal mucosa $(69.1 \%$ versus $2.9 \%, P<0.001)$. Significant correlations were only found between high levels of MMP-9 expression and metastasis of lymph nodes and Dukes' stage. Overexpression of MMP-9 was associated with shorter survival times in univariate analysis. Multivariate analysis confirmed that MMP-9 expression was an independent prognostic factor.

Conclusions: MMP-9 is correlated with the metastasis of lymph nodes, and its elevated expression may be an adverse prognostic indicator for the patients of colon cancer.
\end{abstract}

Keywords: Matrix metalloproteinase-9, Colon cancer, Immunohistochemistry

\section{Background}

Colon cancer is the most frequent digestive system cancer in the world. It is also the third most common malignant tumor in the United States. In 2012, the estimated new cases of colon cancer were 103,170 throughout the country [1]. With the development of economy and the changes in dietary patterns, the incidence of colon cancer is also increasing rapidly in China. Now, colon cancer is the fourth most common malignant tumor and the third leading cause of cancer death in Chinese people [2].

The invasion and metastasis of cancer cells always result in treatment failure. Extracellular matrix (ECM)

\footnotetext{
*Correspondence: whzyyfjm@163.com; whzyyrzg@163.com

${ }^{\dagger}$ Equal contributors

${ }^{3}$ Department of Pathology, Wuhan General Hospital of Guangzhou

Command PLA, 627 Wuluo Road, Wuchang District, Wuhan 430070, China

'Department of Oncology, Wuhan General Hospital of Guangzhou

Command PLA, 627 Wuluo Road, Wuchang District, Wuhan 430070, P.R.

China

Full list of author information is available at the end of the article
}

degradation is an important stage of tumor metastasis, which is regulated with matrix metalloproteinases (MMPs) $[3,4]$. The MMPs carry out the selective proteolytic degradation of ECM, which is an imperative step for the migration and invasion of tumor cells. MMPs are divided into six categories according to the specificity of their substrates as follow: interstitial collagenases, gelatinases, stromelysins, matrilysins, membrane-type MMPs and others [5]. MMP-9 is an important member of the gelatinases. It is also called gelatinase B or $92 \mathrm{kDa}$ type IV collagenase [6]. The gene of MMP-9 is located in 20q11.2-q13.1. MMP-9 can be involved in the development of several human malignancies, as degradation of collagen IV in the basement membrane and the extracellular matrix facilitates tumor progression, including invasion, metastasis, growth and angiogenesis [7].

However, the correlation between MMP-9 expression and survival or prognosis in colon cancer is still inconclusive. Here, we immunohistochemically investigated 68 
specimens of colon cancer tissues and corresponding distal normal mucosa tissues. Then, the association of MMP-9 expression with clinicopathologic features and prognosis was analyzed by univariate and multivariate analysis. The results of this study could provide new evidence for the research of MMP-9 in colon cancer.

\section{Methods}

\section{Ethics statement}

The study was approved by the Wuhan General Hospital Ethical Committee. Written informed consent was obtained from all participants.

\section{Patients and tissue samples}

Colon cancer tissues and corresponding distal normal mucosa tissues of 68 patients who were treated at Wuhan General Hospital of Guangzhou Command PLA between January 2005 and January 2007 served as the study material. Diagnosis and staging were performed according to the modified Dukes' classification [8]. Forty-four patients were men and 24 patients were women. The mean age was 58 years with a range of 47 to 70 years. The depth of invasion was classified as mucosal and submucosal membrane layer, muscular layer and serosa layer. Tumors were classified as well, moderately and poorly differentiated adenocarcinomas. Lymph node metastasis happened in 27 patients, and the other 41 patients had no metastatic lymph nodes. All patients were followed up for survival. None of the patient underwent radiotherapy or chemotherapy before surgery. Formalin-fixed and paraffinembedded surgical tissue samples were collected from the archives of the Department of Pathology, Wuhan General Hospital of Guangzhou Command.

\section{Immunohistochemistry}

The paraffin-embedded colon cancer tissues and corresponding distal normal mucosal tissues were cut at $4 \mu \mathrm{m}$ and mounted on glass slides. Then, the slides were dewaxed in xylene and rehydrated in ethanol, and treated with a solution of peroxidase-blocking reagent (Dako, Glostrup, Denmark) to exhaust endogenous peroxidase activity. They were put in $0.01 \mathrm{~mol} / \mathrm{L}$ citrate buffer at $\mathrm{pH} 6.0$ for $15 \mathrm{mi}-$ nutes in an $800 \mathrm{~W}$ microwave oven and then left at room temperature for 20 minutes to expose antigen hidden inside the tissue due to formalin fixation. To inhibit nonspecific antigen-antibody reactions possible in immunohistochemical staining, protein blocker (Research Genetics, Huntsville, AL, USA) was used for 5 minutes, and the slides were washed thoroughly with PBS buffer. Then the slides were incubated overnight with the primary antibodies against MMP-9 (1:500; mouse monoclonal antibody, sc-21733, Santa Cruz Biotechnology, Inc., Santa Cruz, USA) at $4^{\circ}$ centigrade. Biotinylated goat anti-mouse secondary antibody (1:200; BA1001, Boster Bio-engineering Limited Company, Wuhan, China) was applied for 20 minutes at room temperature, followed by further washing with buffer to remove unbound antibody. A complex of avidin with horseradish peroxidase was then applied for $20 \mathrm{mi}-$ nutes at room temperature. For color development, the slides were stained with 3,3'-diaminobenzidine tetrahydrochloride (DAB, Sigma-Aldrich, St Louis, MO, USA), then counterstained with hematoxylin. A reddish brown precipitate in the cytoplasm of cells indicated a positive reaction. In each immunohistochemistry run, the positive section provided by the reagent company served as the positive control, and omission of the primary antibody served as negative control. Immunohistochemistry stained slides were reviewed by two investigators independently blinded to all clinical data. A scoring system was used to

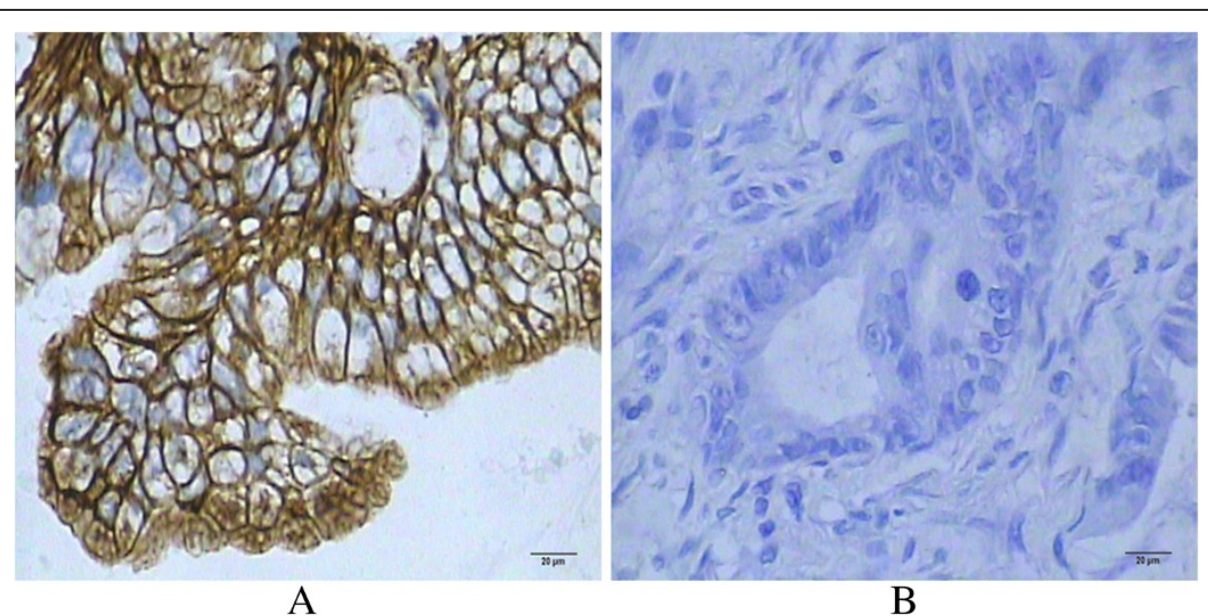

Figure 1 Matrix metalloproteinase-9 (MMP-9) expression in colon cancer tissues. A: Positive MMP-9 expression in colon cancer tissue. The expression of MMP-9 was detected in the cytoplasm by immunohistochemistry staining ( $\times 400$, SP method). B: Negative MMP-9 expression in colon cancer tissue $(\times 400, \mathrm{SP}$ method). 
describe both intensity of staining ( 0 , negative; 1 , weak; 2 , moderate; 3 , strong) and the percentage of cells stained ( 0 , $0 \% ; 1,1 \%$ to $5 \% ; 2,6 \%$ to $75 \% ; 3,76 \%$ to $100 \%)$. The final score was determined by the combined staining score (extent + intensity) [9]. Score $\geq 3$ was defined as positive expression.

\section{Statistical analysis}

MMP-9 expressions in colon carcinoma and normal mucosa were compared by $\chi^{2}$ test. The $\chi^{2}$ test was also used to examine MMP-9 expressions in various clinicopathological characteristics. The univariate survival analysis and cumulative survival curve were executed by Kaplan-Meier method. The difference between the curves was analyzed by Logrank test. The multivariate survival analysis was executed by Cox proportional hazard regression model. A $P$ value $<0.05$ was considered statistically significant. All statistical analyses were performed with SPSS 13.0 (SPSS Inc., Chicago, IL, USA).

\section{Results}

Matrix metalloproteinase-9 expression in colon carcinoma and distal normal mucosa

Positive MMP-9 expression was observed in 69.1\% (47/68) of the colon cancer tissues, and in 4.4\% (3/68) of the distal normal mucosal tissues (Figure 1). The expression of MMP-9 was detected in the cytoplasm. The difference of MMP-9 expression between colon cancer and distal normal mucosa was statistically significant ( $\mathrm{X} 2=64.602, P<0.001$ ).

Correlation of matrix metalloproteinase-9 expression and clinicopathological features in colon cancer

When comparing the MMP-9 status with clinicopathological variables, we found significant positive correlations between MMP-9 expression and lymph node metastasis $(P=0.020)$, and Dukes' stage $(P=0.029)$ (Table 1$)$. KaplanMeier analysis showed that the differences of survival in the MMP-9 expression group and the Dukes' stage group were highly statistically significant (Log-rank test, 11.010, $P=0.001$; Log-rank test, 11.831, $P=0.001$ ). Meanwhile, the differences of survival in metastasis of lymph node groups and infiltrative depth groups were also statistically significant (Table 2). Importantly, there were no significant differences between the three groups in terms of patient age, gender and tumor differentiation. The MMP-9 expression appeared as a significantly independent prognostic factor $(P=0.008)$ with a relative risk of 1.857 (95\% confidence interval, 1.117 to 3.088) in Cox multivariate analysis, which was done with the following variables for each case: MMP9 expression, metastasis of lymph node, infiltrative depth, and Dukes' stage (Table 3).
Table 1 The correlation of matrix metalloproteinase-9 (MMP-9) expression and clinicopathological features in colon cancer patients

\begin{tabular}{|c|c|c|c|c|}
\hline \multirow{2}{*}{ Items } & \multirow{2}{*}{ Cases } & \multicolumn{3}{|c|}{ MMP-9 } \\
\hline & & Positive cases & $x^{2}$ & $P$ \\
\hline \multicolumn{5}{|l|}{ Gender } \\
\hline Male & 44 & 32 & \multirow{2}{*}{0.761} & \multirow{2}{*}{0.383} \\
\hline Female & 24 & 15 & & \\
\hline \multicolumn{5}{|l|}{ Age } \\
\hline$<58$ years & 32 & 21 & \multirow{2}{*}{0.345} & \multirow{2}{*}{0.557} \\
\hline$\geq 58$ years & 36 & 26 & & \\
\hline \multicolumn{5}{|l|}{ Tumor size } \\
\hline$<5 \mathrm{~cm}$ & 41 & 27 & \multirow{2}{*}{0.515} & \multirow{2}{*}{0.473} \\
\hline$\geq 5 \mathrm{~cm}$ & 27 & 20 & & \\
\hline \multicolumn{5}{|l|}{ Differentiated degree } \\
\hline Well differentiated & 32 & 23 & \multirow{3}{*}{1.144} & \multirow{3}{*}{0.565} \\
\hline Moderately differentiated & 19 & 14 & & \\
\hline Poorly and undifferentiated & 17 & 10 & & \\
\hline \multicolumn{5}{|l|}{ Infiltrative depth } \\
\hline Mucosa and submucosal layer & 11 & 5 & \multirow{3}{*}{5.872} & \multirow{3}{*}{0.053} \\
\hline Muscular layer & 24 & 15 & & \\
\hline Serosa layer & 33 & 27 & & \\
\hline \multicolumn{5}{|l|}{ Metastasis of lymph node } \\
\hline Negative & 41 & 24 & \multirow{2}{*}{5.416} & \multirow{2}{*}{$0.020^{*}$} \\
\hline Positive & 27 & 23 & & \\
\hline \multicolumn{5}{|l|}{ Dukes' stage } \\
\hline A & 11 & 4 & \multirow{4}{*}{9.051} & \multirow{4}{*}{$0.029 *$} \\
\hline B & 30 & 20 & & \\
\hline C & 17 & 14 & & \\
\hline$D$ & 10 & 9 & & \\
\hline
\end{tabular}

*Statistically significant.

Relationship between matrix metalloproteinase-9 expression and survival rate of colon cancer patients

The 5-year survival rate for 68 colon cancer patients was $57.4 \%$. The 5-year survival rates for MMP-9 negative and MMP-9 positive cases were $67.6 \%$ and $41.9 \%$, respectively. The difference of survival rate between the MMP-9

Table 2 Results of survival analysis for individual factors

\begin{tabular}{lcc}
\hline Factor & Log rank & $\boldsymbol{P}$ \\
\hline Matrix metalloproteinase-9 (MMP-9) expression & 11.010 & $0.001^{*}$ \\
Gender & 0.520 & 0.471 \\
Age & 0.041 & 0.839 \\
Tumor differentiation & 0.055 & 0.814 \\
Metastasis of lymph node & 8.687 & $0.003^{*}$ \\
Infiltrative depth & 6.141 & $0.013^{*}$ \\
Dukes' stage & 11.831 & $0.001^{*}$ \\
\hline
\end{tabular}

*Statistically significant. 
Table 3 Results of Cox multivariate regression factors

\begin{tabular}{lcc}
\hline Factor & Wald value & $\boldsymbol{P}$ value \\
\hline Matrix metalloproteinase-9 (MMP-9) expression & 5.698 & $0.017^{*}$ \\
Metastasis of lymph node & 0.378 & 0.539 \\
Infiltrative depth & 0.159 & 0.690 \\
Dukes' stage & 6.597 & $0.010^{*}$ \\
\hline
\end{tabular}

*Statistically significant.

negative group and the MMP-9 positive group was statistically significant (Log-rank test $=11.010, P=0.001$ ) (Figure 2).

\section{Discussion}

Colon cancer is one of the most familiar malignant neoplasmas. The pathogenesis of tumor is a process of multiple factors, multiple steps and many stages, which are concerned with the abnormalities of many oncogenes, tumor suppressor genes, mismatch repair genes and cellular adhesive factors [10]. But the invasion and metastasis of tumor cells were main causes for cancer treatment failure among these factors. MMP-9 is the most complex member of the MMPs family in terms of domain structure. It is capable of degrading decorin, elastin, fibrillin, laminin, gelatin, and types IV, V, XI and XVI collagen $[11,12]$. The expression of MMP-9 was regulated by many upstream factors. Levels of phosphorylated signal transducer and activator of transcription 3(STAT3) regulated the MMP-9 gene in pediatric patients with ulcerative colitis [13]. Ursolic acid (UA), a natural pentacyclic triterpenoid carboxylic acid distributed in medical herbs, also suppressed colon cancer cell migration by inhibiting MMP-9 expression [14]. Increased $\mathrm{CO}_{2}$ concentration also elevated the mRNA expression of MMP-9 and invasive capability in colon cancer cell lines and human samples derived from a peritoneal metastasis [15]. Knockdown of metastasis-associated in colon cancer 1 (MACC1) expression using shRNA reduced hepatocellular carcinoma Huh7 cell migration and invasion abilities, which were associated with the downregulation of MMP-9 protein [16]. Detected by using a luciferase reporter construct and western blots, piwi-like protein 2 (Piwil2) may regulate a 2-kb MMP-9 promoter fragment and apoptotic pathways in colon cancer [17].

Overexpression of MMP-9 has been found to associate with the invasion and metastasis of cancer [18]. The level of MMP-9 expression showed a statistically significant correlation $(P<0.001)$ with the disease histopathologic grade, stage, metastatic potential, recurrence potential, and survival in patients with squamous cell carcinoma of the larynx. The Kaplan-Meier curve linearly showed the MMP-9 expression as a predictor of survival to be significantly $(P<0.001)$ associated with survival [19].

The increased MMP-9 expression makes the main contribution to the invasive potential of squamous cell cervical carcinomas [20]. Elevated serum MMP-9 correlated with distant metastasis and poor survival in patients with squamous cell carcinoma (SCC) over either the head and neck or the esophagus [21]. Elevated serum MMP-9 level was also associated with reduced diseasefree survival (DFS) of breast cancer [22].

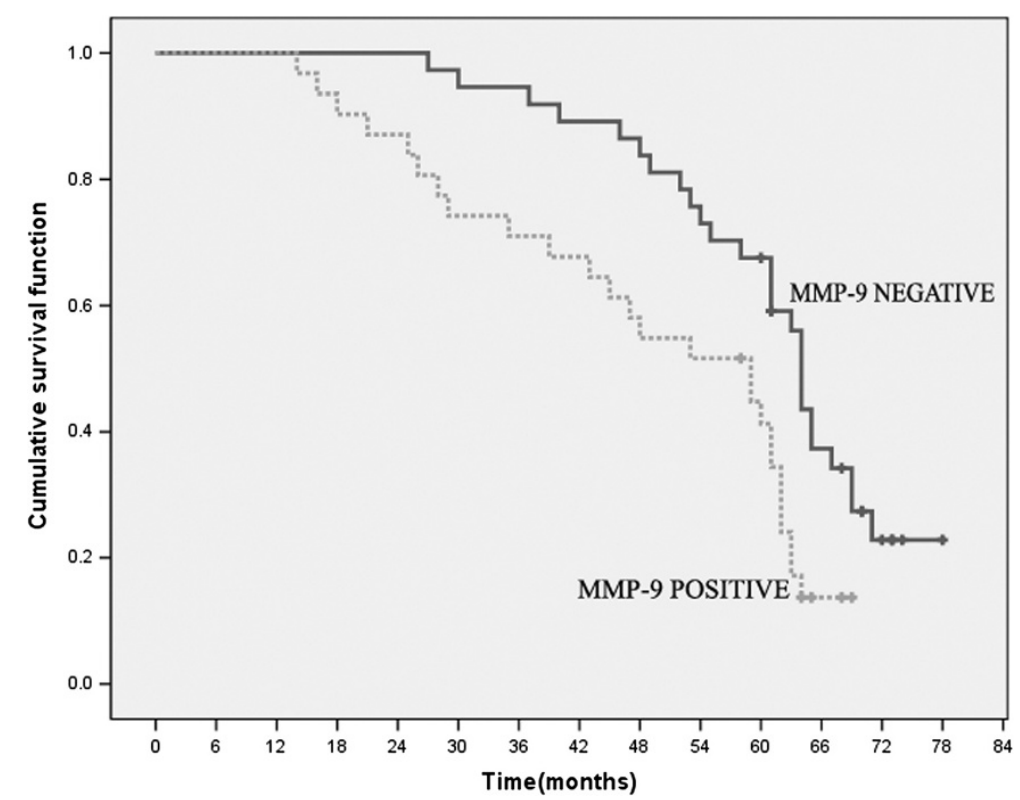

Figure 2 Kaplan-Meier survival plots of matrix metalloproteinase-9 (MMP-9) positive group and negative group. There is highly significant difference in survival rate between the MMP-9 negative group and the MMP-9 positive group (Log-rank test $=11.010, P=0.001$ ). 
In this study, we found that MMP-9 expression in colon cancer tissues $(47 / 68,69.1 \%)$ was significantly higher than that in corresponding distal normal mucosa tissues $(3 / 68$, $4.4 \%)$, and there was a statistically significant difference ( $x^{2}=64.602, P<0.001$ ) between them. Furthermore, high levels of MMP-9 expression in colon cancer cells correlated with lymph node metastasis and with Dukes' stage. Therefore, these findings suggested that MMP-9 was likely to play a role in promoting tumor invasion and metastasis. Meanwhile, Kaplan-Meier analysis showed that the differences of survival in metastasis of lymph node groups, infiltrative depth groups, MMP-9 expression group and Dukes' stage group were highly statistically significant. Cox multivariate analysis suggested that MMP-9 might serve as an independent marker for poor prognosis. Unsal $\mathrm{D}$ et al. reported that MMP-9 expression was characterized by poor overall survival and DFS in patients with Stage II/III rectal carcinoma [23]. Here, our results showed that MMP-9 might be correlated with the metastasis of lymph node, and its elevated expression might be an adverse prognostic indicator for the patients of colon cancer. Although the detailed molecular mechanism involved in this process is less well defined, this study still has potential clinical benefits. The MMP-9 expression that could be detected by immunohistochemistry may be a useful molecular marker to predict the prognosis in colon cancer patients.

\section{Conclusions}

In conclusion, our study suggests that MMP-9 plays an important role in invasion and metastasis of colon cancer, and thus becomes a useful indicator for clinical assessment of tumor biological behavior and prognosis in colon cancer patients.

\section{Abbreviations \\ DAB: 3,3'-diaminobenzidine tetrahydrochloride; DFS: disease-free survival; ECM: extracellular matrix; MACC1: metastasis-associated in colon cancer 1; MMP-9: matrix metalloproteinase-9; MMPs: matrix metalloproteinases; Piwil2: piwi-like protein 2; SCC: squamous cell carcinoma; STAT3: signal transducer and activator of transcription 3; UA: ursolic acid.}

\section{Competing interests}

The authors declare that they have no competing interests.

\section{Authors' contributions}

BY drafted the manuscript. JF and ZR designed the study and helped in drafting the manuscript. FT, BZ, and YZ collected the data and performed the statistical analysis. All authors have read and approved the final manuscript.

\section{Acknowledgements}

This work was supported by grants from National Natural Science Foundation of China (NO. 81201933) and Youth Foundation of Wuhan General Hospital (NO. 201141).

\section{Author details}

'Department of Oncology, Wuhan General Hospital of Guangzhou Command PLA, 627 Wuluo Road, Wuchang District, Wuhan 430070, P.R. China. ${ }^{2}$ Second Department of Cadres, Wuhan General Hospital of Guangzhou Command PLA, 627 Wuluo Road, Wuchang District, Wuhan
430070, P.R. China. ${ }^{3}$ Department of Pathology, Wuhan General Hospital of Guangzhou Command PLA, 627 Wuluo Road, Wuchang District, Wuhan 430070, China.

Received: 20 November 2013 Accepted: 18 January 2014

Published: 29 January 2014

\section{References}

1. Siegel R, Naishadham D, Jemal A: Cancer statistics, 2012. CA Cancer J Clin 2012, 62:10-29.

2. Long N, Moore MA, Chen W, Gao CM, Lai MS, Mizoue T, Oyunchimeg D, Park S, Shin HR, Tajima K, Yoo KY, Sobue T: Cancer epidemiology and control in north-east Asia - past, present and future. Asian Pac J Cancer Prev 2010, 11(Suppl 2):107-148.

3. Duffy MJ, Maguire TM, Hill A, McDermott E, O'Higgins N: Metalloproteinases: role in breast carcinogenesis, invasion and metastasis. Breast Cancer Res 2000, 2:252-257.

4. Stetler-Stevenson WG, Yu AE: Proteases in invasion: matrix metalloproteinases. Semin Cancer Biol 2001, 11:143-152.

5. Aznavoorian S, Murphy AN, Stetler-Stevenson WG, Liotta LA: Molecular aspects of tumor cell invasion and metastasis. Cancer 1993, 71:1368-1383.

6. Forsyth PA, Wong H, Laing TD, Rewcastle NB, Morris DG, Muzik H, Leco K, Johnston RN, Brasher PM, Sutherland G, Edwards DR: Gelatinase-A (MMP2), gelatinase-B (MMP-9) and membrane type matrix metalloproteinase-1 (MT1-MMP) are involved in different aspects of the pathophysiology of malignant gliomas. Br J Cancer 1999, 79:1828-1835.

7. Groblewska M, Siewko M, Mroczko B, Szmitkowski M: The role of matrix metalloproteinases (MMPs) and their inhibitors (TIMPs) in the development of esophageal cancer. Folia Histochem Cytobiol 2012, 50:12-19.

8. Kyriakos M: The President's cancer, the Dukes classification, and confusion. Arch Pathol Lab Med 1985, 109:1063-1066.

9. Curran S, Dundas SR, Buxton J, Leeman MF, Ramsay R, Murray GI: Matrix metalloproteinase/tissue inhibitors of matrix metalloproteinase phenotype identifies poor prognosis colorectal cancers. Clin Cancer Res 2004, 10:8229-8234.

10. Jenab M, Bueno-de-Mesquita HB, Ferrari P, van Duijnhoven FJ, Norat T, Pischon T, Jansen EH, Slimani N, Byrnes G, Rinaldi S, Tjonneland A, Olsen A, Overvad K, Boutron-Ruault MC, Clavel-Chapelon F, Morois S, Kaaks R, Linseisen J, Boeing H, Bergmann MM, Trichopoulou A, Misirli G, Trichopoulos D, Berrino F, Vineis P, Panico S, Palli D, Tumino R, Ros MM, van Gils $\mathrm{CH}$, et al: Association between pre-diagnostic circulating vitamin $\mathrm{D}$ concentration and risk of colorectal cancer in European populations:a nested case-control study. BMJ 2010, 340:b5500.

11. Westermarck J, Kahari VM: Regulation of matrix metalloproteinase expression in tumor invasion. FASEB J 1999, 13:781-792.

12. Murphy G, Docherty AJ: The matrix metalloproteinases and their inhibitors. Am J Respir Cell Mol Biol 1992, 7:120-125.

13. Koukos G, Polytarchou C, Kaplan JL, Morley-Fletcher A, Gras-Miralles B, Kokkotou E, Baril-Dore M, Pothoulakis C, Harland SW, lliopoulos D: MicroRNA-124 regulates STAT3 expression and is down-regulated in colon tissues of pediatric patients with Ulcerative colitis. Gastroenterology 2013, 145:842-852.

14. Wang J, Liu L, Qiu H, Zhang X, Guo W, Chen W, Tian Y, Fu L, Shi D, Cheng J, Huang W, Deng W: Ursolic Acid simultaneously targets multiple signaling pathways to suppress proliferation and induce apoptosis in colon cancer cells. PLoS One 2013, 8:e63872.

15. Obata S, Goi T, Nakazawa T, Kimura Y, Katayama K, Yamaguchi A: Changes in $\mathrm{CO} 2$ concentration increase the invasive ability of colon cancer cells. Anticancer Res 2013, 33:1881-1885.

16. Gao J, Ding F, Liu Q, Yao Y: Knockdown of MACC1 expression suppressed hepatocellular carcinoma cell migration and invasion and inhibited expression of MMP2 and MMP9. Mol Cell Biochem 2013, 376:21-32.

17. Li D, Sun X, Yan D, Huang J, Luo Q, Tang H, Peng Z: Piwil2 modulates the proliferation and metastasis of colon cancer via regulation of matrix metallopeptidase 9 transcriptional activity. Exp Biol Med (Maywood) 2012, 237:1231-1240.

18. Page-McCaw A, Ewald AJ, Werb Z: Matrix metalloproteinases and the regulation of tissue remodelling. Nat Rev Mol Cell Biol 2007, 8:221-233.

19. Colovic Z, Pesutic-Pisac V, Poljak NK, Racic G, Cikojevic D, Kontic M: Expression of matrix metalloproteinase-9 in patients with squamous cell carcinoma of the larynx. Coll Antropol 2013, 37:151-155. 
20. Ryzhakova OS, Zavalishina LE, Andreeva I, Solov'eva NI: Interstitial collagenase, gelatinases $A$ and $B$ and their endogenous inhibitors in squamous cell cervical carcinomas. Biomed Khim 2013, 59:55-64.

21. Wang WL, Chang WL, Yeh YC, Lee CT, Chang CY, Lin JT, Sheu BS:

Concomitantly elevated serum matrix metalloproteinases 3 and 9 can predict survival of synchronous squamous cell carcinoma of the upper aero-digestive tract. Mol Carcinog 2013, 52:438-445.

22. Sung H, Choi JY, Lee SA, Lee KM, Han S, Jeon S, Song M, Lee Y, Park SK, Yoo KY, Noh DY, Ahn SH, Kang D: The association between the preoperative serum levels of lipocalin-2 and matrix metalloproteinase-9 (MMP-9) and prognosis of breast cancer. BMC Cancer 2012, 12:193.

23. Unsal D, Akyurek N, Uner A, Erpolat OP, Han U, Akmansu M, Mentes BB, Dursun $A$ : Gelatinase B expression as a prognostic factor in patients with stage II/III rectal carcinoma treated by postoperative adjuvant therapy. Am J Clin Oncol 2008, 31:55-63.

doi:10.1186/1477-7819-12-24

Cite this article as: Yang et al:: Matrix metalloproteinase-9 overexpression is closely related to poor prognosis in patients with colon cancer. World Journal of Surgical Oncology 2014 12:24.

\section{Submit your next manuscript to BioMed Central and take full advantage of:}

- Convenient online submission

- Thorough peer review

- No space constraints or color figure charges

- Immediate publication on acceptance

- Inclusion in PubMed, CAS, Scopus and Google Scholar

- Research which is freely available for redistribution 